\title{
Обратите внимание!
}

\section{Статья отозвана (ретрагирована)}

\section{Статья}

Безбородов В.Г., Дукарский О.М., Тряпкин Д.С., Ушаков Р.Г. Организация массового доступа к пространственной информации и её анализ в интересах развития территорий // Интернет-журнал «Отходы и ресурсы» Том 2, №4 (2015) http://resources.today/PDF/04RRO415.pdf (доступ свободный). Загл. с экрана. Яз. рус., англ.

\section{отозвана (ретрагирована) редакцией журнала в соответствии с правилами отзыва (ретракции) Интернет-журнала «Отходы и ресурсы» http://resources.today/retraction.html}

\section{В ходе дополнительной проверки выяснилось, что статья уже была опубликована ранее:}

Безбородов В.Г., Дукарский О.М., Тряпкин Д.С., Ушаков Р.Г. Организация массового доступа к пространственной информации и её анализ в интересах развития территорий // Интернет-журнал «НАУКОВЕДЕНИЕ» Том http://naukovedenie.ru/PDF/123EVN415.pdf (доступ свободный). Загл. с экрана. Яз. рус., англ.

\section{Редакция приносит извинения читателям за доставленные неудобства}


Интернет-журнал «Отходы и ресурсы» / Russian journal of resources, conservation and recycling http://resources.today 2015, Том 2, №4 / 2015, Vol 2, No 4 http://resources.today/issues/vol2-no4.html

URL статьи: http://resources.today/PDF/04RRO415.pdf

DOI: 10.15862/04RRO415 (http://dx.doi.org/10.15862/04RRO415)

Ссылка для цитирования этой статьи:

Безбородов В.Г., Дукарский О.М., Тряпкин Д.С., Ушаков Р.Г. Организация массового доступа к пространственной информации и её анализ в интересах развития территорий // Интернет-журнал «О peсурсы» Том 2, №4 (2015) http://resources.today/PDF/04RRO415.pdf (доступ свободный). Загл. экрина. Яз. рус., англ.

For citation:

Bezborodov V.G., Dukarskiy O.M., Tryapkin D.S., Ushakov R.G. [Organization of mass acces tro spatial information and its analysis for territorial development] Russian journal of resources, conservation and raycing, 2015, Vol. 2, no. 4. Available at: http://resources.today/PDF/04RRO415.pdf (In Russ.)

\section{УДК 644.6}

Безборо ав Вячеслав Георгиевич ФГБОУ ВПО «Российский государственный универси ет туризма и сервиса», Россия, Москва Заведующий базовой кафєдрой «Геоинформационного сервиса» ОАО «Научно-производственна " корпорация «РЕКОД», Россия, Москва ${ }^{1}$ Генеральный директор Кандидат военных наук E-mail: bezborodov@ recod.ru

Дукарский Олег Меерович ОАО «Научно-производственная корпорация «РЕКОД», Россия, Москва Главный научный сотрудник Доктор технических наук, профессор E-mail: dukarsky@ rekod.ru

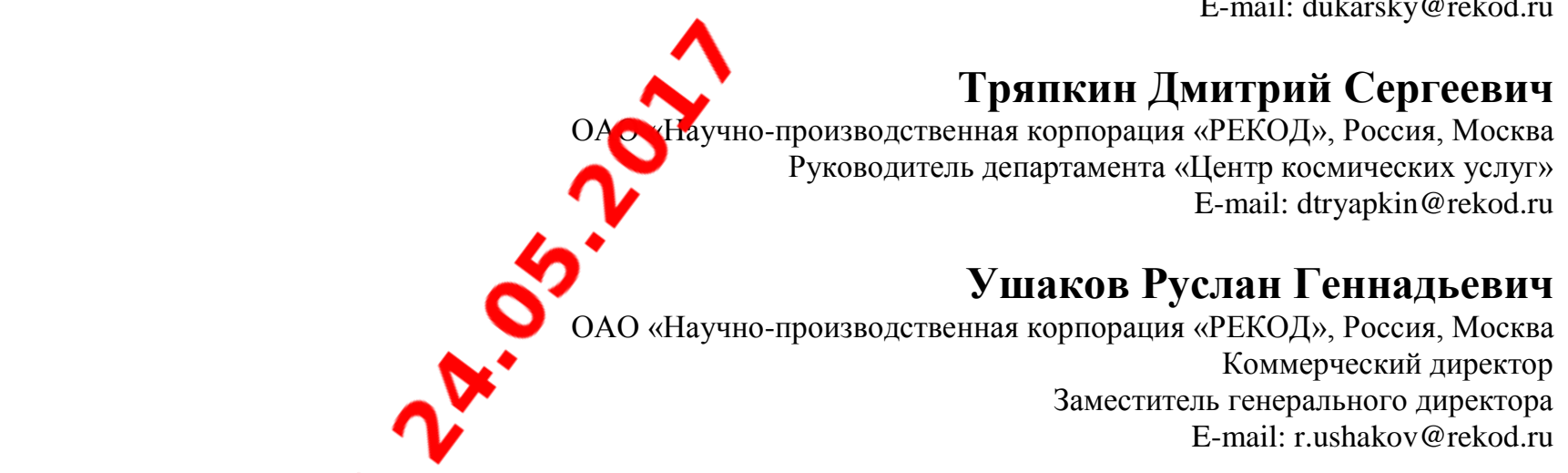

\section{Организаһия массового доступа к пространственной информаку и её анализ в интересах развития территорий}

Аннот Ая. Рассматриваются вопросы широкого доступа к космической информации органов уддарственного управления регионом и местного самоуправления, обеспечи ва ощего повышение качества управленческих решений.

Плдробно рассматриваются вопросы покрытия площади региона космическими сник кә ми различного разрешения и ориентировочная стоимость таких работ.

\footnotetext{
${ }^{1}$ www.rekod.ru
} 
Описываются функции, приводящие космическую информацию к виду, интенсифицирующему деятельность лиц, принимающих решения (дополнительные альтернативы), и наглядность принимаемых решений.

На основе анализа вышеназванных функций делается вывод, что широкий до космической информации возможен при организации специальных подраз пений, реализующих эти функции в регионах, которые получили название «центр ко ических услуг».

Общими требованиями к центру космических услуг названы следуюшяе:феализация простого, постоянного и быстрого доступа лиц, принимающих решения, к поос ранственной информации с обеспечением максимально достижимой её актуальности, темм ический анализ пространственной информации и обеспечение разнообразия форм её пред тав̈ления, участие в реализации навигационных задач.

Рассматриваются региональные и муниципальные центры космических услуг.

Региональные центры определяются как оператор, предос ззлющий в рамках региона возможность оперативного предоставления всем заинтересоваю ым пользователям в зоне его ответственности высокоточной и достоверной информации В единой системе координат и реальном времени. Основными потребителями инфюпмации являются структурные подразделения субъектов Российской Федерации, а также рганы местного самоуправления муниципальных образований.

Муниципальный центр определён как қедство информационной поддержки муниципального управления и предназначен для - оучения и комплексного использования органами местного самоуправления космическом информации для поддержки принятия управленческих решений.

Показано, что при наличии региональных центров космических услуг существование отдельных муниципальных центров космических услуг затратно и неэффективно, поэтому предлагается подготовку пространственнй информации как в интересах региона, так и в интересах муниципальных образований јсуществлять в региональных центрах космических услуг с последующей передачей её н.порталы муниципальных образований.

Отмечен позитивный контакт региональных центров космических услуг с ОАО «НПК «РЕКОД», в первую очередь э иетодическая помощь, а также возможная технологическая помощь для решения сложнь Р $а$ дач.

Прогнозируется, чр дальнейшее развитие сети региональных центров космических услуг во многом завис ат доступности данных дистанционного зондирования Земли на основе космоснимков высокого разрешения с отечественных космических аппаратов.

Ключевые с.ва: дистанционное зондирование Земли; доступ к космической информации; пр странственная информация; покрытие территории космоснимками; управление терр \$ эрией; центр космических услуг

Ш оий доступ массового потребителя к космической информации (КИ) требует новых оодов как с точки зрения организации и технологии поставки, так и с позиций потреюиюля данных ДЗ3 (ДДЗ3), особенно в регионах при принятии решений.

Как известно, результаты космической деятельности (РКД) - устойчивый термин, под которым принято понимать результат использования технологий спутниковых навигационных систем и получение данных дистанционного зондирования Земли, а также 
использование разнообразных информационных, программных, аппаратных, программноаппаратных и технических решений на базе этих технологий.

Комплексное использование РКД в работе отраслевых компаний способно придать инновационный характер, усилить конкурентные преимущества, повысить эффектид ость производства, строительства, снизить затраты и оптимизировать многие п्мшессы управления. Аналогично, применение РКД для управления территориями откр ает для любого решения по ликвидации проблем новые аспекты, как правило, резко прышающие эффективность работы лиц, принимающих решения (ЛПР).

Стандартные пути доступа массового пользователя к дДз3 уже сегалю обеспечены достаточными механизмами получения необходимых снимков из разли іх источников путём их предварительного заказа на договорной основе. Стоим си снимков для пользователя во многом зависит от цели их приобретателя. Если реш ался задачи в рамках проектов, обещающих высокую эффективность (градостроительные, кадастровые и т.п.), то в общей технологической цепочке стоимость снимков вряд ли ст не препятствием для их приобретения. Сроки поставки архивных снимков для таких ддач также можно считать приемлемыми. Обычно такие проекты сопровождаются ялифицированным составом исполнителей, для которых организация геоинформационног анализа не является какой-либо серьёзной преградой.

Совершенно по-иному выглядят эти вопросы, сопровождение (картирование) потока принятия рє жений ЛПР в регионе, тем более в муниципальном образовании.

Картирование резко повышает качес \$- принимаемых решений, даже по традиционным вопросам. Однако для того, чтобы обеспечить пространственной информацией ряд проблем, с которыми работают ЛПР (например, задачи, возникающие как последствия инцидентов, доставка детей в школы из отдалённых районов, обеспечение сельских жителей медицинской помощью и многие другия задачи), возможностей современного доступа к пространственной информации недостапючно. Обычно, получив задание по решению проблемы, ЛПР должно оперативно гото:ить решение, для чего ему необходимо иметь почти немедленно доступ к пространственн данным, или информацию о том, что это невозможно по объективным причинам. Кроме т ro, будут возникать вопросы оплаты такой информации, если доступ к необходимым фмюснимкам исключительно коммерческий, а для снимков высокого разрешения это квалифицированного подхода, акже может явиться препятствием для ЛПР.

В среднесрочной использования простран њенной информации при принятии решений в регионе является специально организс мная электронная карта (точнее - план) с достижимым масштабом не менее 1:2000, покь јающая целиком регион. При этом объекты мониторинга в процессе инвентаризации (१к правило, это первая задача в тематической группе технологий, использующих в зльтаты космической деятельности - РКД-Т) образуют соответствующие тематически з кторные слои с набором атрибутивной информации. В настоящее время достичь так, картографической поддержки достаточно сложно, да и в этом нет острой необходг мости. Планы масштаба 1:2000 и более крупные полезны для населённых пунктов, которь например, в областях нечерноземья не превышают 3\% общей площади. Масштаб для РКД зависит от задач, которые могут быть решены с применением электронных карт. Так, для задач возможен и более мелкий масштаб. Таким образом, на сегодня достижимым является «кусочное» (разномасштабное) покрытие территории региона. 
Всё вышесказанное показывает, что подготовительная работа по предоставлению ЛПР оперативной картированной информации требует непрерывной подготовительной работы с дистрибьюторами, организации работы с ГИС-пакетами, обеспечивающими создание «кусочной» электронной карты, её хранение, создание тематических слоёв и актуалиэяцию информации. Более того, необходимо актуализировать информацию по объектам кажжого тематического слоя, используя при этом в том числе данные региональных сервисов ағакже данные региональных отделений федеральных служб, таких как Росреестр, Росста ФНС и т.д.

Далее необходимо понять стоимость первичного покрытия региою? предполагая только коммерческий доступ к КИ. В качестве примера рассмотрим Ки о скую область, площадь которой составляет около 120400 кв. км. При этом оценим ктокмость архивных космоснимков высокого разрешения для городских округов (име но такие снимки необходимы для решения социально-экономических задач).

Площади, занимаемые основными городами области, состав ЯF т 329,2 кв. км (г. Киров - 169,7 кв. км., г. Кирово-Чепецк - 53,4 кв. км, г. Слободской -496 кв. км, г. Котельнич $-28,5$ кв. км и г. Вятские Поляны - 28 кв. км).

Приобретение архивных снимков, покрывающих эти територии, можно оценить по формуле:

$$
\mathrm{C}=\mathrm{S} * \mathrm{R} * \mathrm{~K}_{1} * \mathrm{~K}_{2}
$$

где: $\mathrm{S}$ - площадь городских поселений;

$\mathrm{R}$ - средняя стоимость 1 кв. км;

$\mathrm{K}_{1}-$ коэффициент, учитывающий взаимное наложение снимков (включая естественный выход крайних от границы снимков за городскую черту), принимает значение 1,3;

$\mathrm{K}_{2}$ - стоимость проведения процедур ортотрансформирования, принимается 1,2.

Стоимость одноразового покр тия только части населённых пунктов Кировской области снимками сверхвысокого рагршения ( $\approx 0,5$ м) составит:

$$
\mathrm{C}_{1}=329 * 2 * 30 * 1,3 * 1,2 \approx 15400 \text { USD, }
$$

где ориентировочная бечмость архивного снимка с разрешением 0,5 - 0,8 м составляет $\approx 30$ USD за 1 кв. к м.

Если учесть все нас пённые пункты области, то площадь, занимаемая ими, не превысит $1 \%$ общей площади (120 кв. км) и, соответственно, стоимость снимков сверхвысокого разрешения не превысит 3200 USD.

Полное покры региона в М1:50000 возможно КА с разрешением 10 м. Стоимость такого покрытия рхивными снимками при удельной стоимости 0,61 USD за 1 кв. км составит:

$$
\mathrm{C}_{2}=120400 * 0,61 * 1,3 * 1,2 \approx 114600 \text { USD. }
$$

Пг жияие снимками среднего разрешения может составить 40\% общей площади областу 48160 кв. км. Стоимость такого покрытия при удельной стоимости 1,4 USD за 1 кв. кмсочтавит:

$$
\mathrm{C}_{3}=48160 * 1,4 * 1,3 * 1,2 \approx 105200 \text { USD. }
$$

Итого, с большим запасом, полное покрытие территории Кировской области космоснимками с учётом применения различных РКД-Т не превышает 276 тыс. USD. 
Ежегодная актуализация может составить до 20\%, то есть не более 56 тыс. USD в год.

Средняя стоимость снимка одного квадратного километра не превысит 2,3 USD.

Для таких регионов, как Московская область, Краснодарский край, средняя стоимость 1 кв. км снимка может вырасти вдвое и более.

Конечно, эти расчёты позволяют представить только общий «порядок» затрат аһ хИ.

Следует отметить, что часть снимков различного разрешения можи получить практически бесплатно.

В частности, для федеральных органов исполнительной вл и и органов исполнительной власти субъектов Российской Федерации - пользователей данных дистанционного зондирования, для обеспечения государственных нужд ध њмические снимки передаются на безвозмездной основе. Плата в таком случае может взим дться за услуги по их тематической обработке [1].

Для этого потребителям, являющимся представителями федеальных и региональных органов исполнительной власти, для оформления заказа на or eparивную (новую) съемку и архивную информацию необходимо обратиться в НЦ ОМЗ ОАО «Российские космические системы», который является Оператором российских косми-ских систем дистанционного зондирования Земли, отраслевым информационным це гром Д3З и центром Единой государственной системы информации об обстано в мировом океане (ЕСИМО) Роскосмоса, и представить заполненные заявки на попу уние данных.

Приведённые выше стоимости и их образ ие свидетельствуют, что для создания покрытия космоснимками и обеспечения в дальнеи тем актуализированной картографической продукцией необходим опыт работы с пространственной информацией, в том числе для применения технологий, использующих результаты космической деятельности (РКД-Т). Также требуется опыт планирования потребностей в снимках различного разрешения с учётом требований к параметрам слики, исходя из рабочих регламентов органов государственного управления в региоғ (ОГУ) и органов местного самоуправления (ОМСУ), а также схем (планов) развития терр в рии, которые в обязательном порядке присутствуют и обновляются в регионе.

Особенно важна прострацственная информация, обеспечивающая работу лиц, принимающих решение (ЛПР, на основе рабочих регламентов. В первую очередь это департаменты ОГУ и подраееления ОМСУ, связанные с экологическим мониторингом (лесное хозяйство, водные ясурсы и др.).

Пространственна унформация должна быть подвергнута дешифровке и анализу, что требует высокой квапификации исполнителя, независимо от того, проводится ручное или автоматизированно ұшифрирование. Именно тематически обработанная пространственная информация и пр४ ставляет интерес для ЛПР.

Всё это Ппеделяет задачу по оптимизации процедур постепенного кусочного покрытия в 8 субъектов региона разномасштабными снимками и ведения архива пространствен ной информации.

Ода вывод, что осуществлять покрытие, проводить актуализацию и сохранять полученую в региональном архиве специально организованную пространственную инф ру ацию должны выполнять специалисты в области обработки и применения результатов космической деятельности в интересах социально-экономического развития территории.

Таким образом, появляется необходимость в некоторой организации-посреднике, обеспечивающей выполнение следующих функций: 
- $\quad$ проведение всех необходимых процедур по доставке потребителям на данной территории космоснимков и другой пространственной информации (картографический материал, данные аэрофотосъёмки, панорамной съёмки для 3D- моделей, видеоматериалы БПЛА и др.). При этом на первых пора - в режиме взаимодействия с дистрибьюторами, пока большая часть территори. не будет покрыта космоснимками. В дальнейшем созданный поспедииком локально-территориальный архив должен обеспечивать до $90 \%$ не пространственной информацией для принятия решений ОГУ и ОMСУ, а также юридических лиц, решающих задачи в рамках территории;

- проведение, где это необходимо, дешифровочных работ, ом числе для некоторых задач, в тесном контакте с ЛПР;

- $\quad$ создание архива пространственных данных, возникаццих как в процессе подготовительных работ для принятия решений ЛПР, так и являющихся результатом принятого решения;

- $\quad$ взаимодействие с отделениями Росреестра, в пе ву очередь по кадастровой информации, которая непрерывно изменяется з счет функционирования рынка недвижимости;

- организация аутсорсинговых услуг пе цспользованию многочисленных сервисов, касающихся проблем, связану Іх РКД-Т (создание и актуализация каталога таких сервисов, технология работы с ними);

- $\quad$ актуализация архивного материала;

- $\quad$ проведение процедур первичной инвентаризации пространственных данных по объектам группы РКД-Т, фактически обогащающих информационную поддержку знаний о территории. В первую очередь, это тематические слои, образующиеся в результа пе процесса инвентаризации пространственных объектов для группы за яч охваченных РКД-Т (водное хозяйство, дорожное хозяйство, лесопользов аи и т.д.) с соответствующими атрибутами объектов;

- предоставление прсслранственной информации ЛПР в режиме, близком к онлайн. Схема такой работы (параметры настройки на проблему, решаемую ЛПР, поиск и пюе оставление пространственной информации, в том числе в интерактивном екиме) будет обсуждаться ниже;

- прогноз и ㄱложение возможных к применению на подведомственной территории РКД-Т и пространственных данных на основе внутренних реглам ттов ОГУ (ОМСУ) и схем развития территорий;

- там тало возможно (зависит от квалификации специалистов посреднической ор-низации), разработка предложений по выходам на социальноro, омические результаты применения РКД-Т (например, прогноз наводнения $1 \%$ жет сопровождаться определением количества населения и социально значимых объектов, попадающих в зону риска);

ликвидация, по возможности, текущей несогласованности цифровых карт и снимков различного масштаба на одну и ту же территорию внутри региона (как правило, муниципального образования) в оперативном режиме;

- обеспечение единой координатной привязки объектов анализа ЛПР, обеспечивающей точность координатного описания; 
- $\quad$ хранение, накопление и актуализация информации о третьей координате в рамках территории, что необходимо для 3D-моделей;

- $\quad$ оперативное 3D-моделирование, в первую очередь, для целей руководства территорией;

- с связь с центральной организацией, объединяющей организации такого посредника на основе оказания консуль дионнометодической помощи.

Кроме того, необходимой функцией является участие в реше навигационных задач на основе технологий ГЛОНАСС.

Можно считать, что в результате реализации приведенных фуғ бй будет создано геоинформационное описание региона, то есть организован геоингр риационный ресурс, обеспечивающий пространственной информацией большую часть спсктра задач принятия решений.

Из вышесказанного вытекают следующие общие требован к такой посреднической организации:

1. Реализация простого, постоянного и быстрог тоступа ЛПР к пространственной информации (ПИ) и обеспечение максималюо постижимой её актуальности.

2. Обеспечение тематического анализа ПИ

3. Обеспечение разнообразия форм предс чғления ПИ.

4. Участие в реализации навигационных эадач.

Таким посредником, осуществляющим массовый доступ потребителей к космической информации, должны стать организуемые ОАО «НПК «РЕКОД» центры космических услуг (ЦКУ).

Центры космических услуг по дтминистративно-территориальным и функциональным признакам подразделяются на секональные (РЦКУ), муниципальные (МЦКУ), информационно-образовательные ОЦКУ) и школьные центры космических услуг (ШЦКУ).

Далее будут рассмотрень элько РЦКУ и МЦКУ и их взаимодействие.

В настоящее время пропсходит развитие сети ЦКУ в регионах, что позволяет ускорить создание масштабного гес формационного описания территории региона с возможностью применения его в любол dере деятельности региона.

Таким образ основным элементом региональной инфраструктуры в области использования РК определены региональные центры космических услуг (РЦКУ), выступающие в ро. и интегрирующего организационно-технологического ядра региональной информационно авигационной системы. Региональные ЦКУ предназначены для предоставлен космических и геоинформационных продуктов и услуг широкому кругу потребителен поддержки принятия управленческих решений и использования РКД на основе передов $\mathbf{X}$ нфокоммуникационных и навигационных технологий.

Оррганизационной точки зрения РЦКУ выполняет следующие уставные функции:

интеграция, сопряжение, целевое использование космической и другой информации от региональных, муниципальных, отраслевых и иных информационных систем; 
- $\quad$ получение, обработка, анализ, систематизация, хранение и организация доступа к оперативным и архивным данным Д33;

- создание картографических тематических продуктов (слоев) на основе разнородной информации;

- $\quad$ ведение автоматизированных баз данных по основным отраслям регионсиной экономики, их интеграция с электронными картами, космо- и аэрос- лкками в интересах мониторинга природопользования, сельского и дорожного

- $\quad$ мониторинг показателей социально-экономического развития pє.14 на основе РКД;

- геоинформационный анализ в интересах ОГВ;

- информационное обеспечение органов государственной ^асти и подготовка управленческих решений.

Итак, РЦКУ можно определить как регионального о бzтора, предоставляющего возможность оперативного предоставления всем заинтересовал пользователям в зоне его ответственности высокоточной и достоверной информации в единой системе координат и реальном времени.

Основными потребителями информации РЦКУ виются структурные подразделения субъектов Российской Федерации, а также органы ме чого самоуправления муниципальных образований.

МЦКУ является средством информационно пाоддержки муниципального управления и предназначен для получения и комплексного использования органами местного самоуправления информации на основе РКД для поддержки принятия управленческих решений, оказания муниципальных услуг населению и осуществления объективного и непрерывного мониторинга и контроля с циально-экономических и экологических процессов на территории муниципального образорания.

Цель создания МЦКУ $\odot$ формирование муниципальной навигационноинформационной системы мунццाпального образования, непрерывно обеспечивающей органы местного самоуправления ьысокоточными и достоверными данными о социальноэкономических процессах на еритории муниципального образования в единой системе координат и реальном времен

Кроме того, МЦКУ Зौяется средством информационного наполнения регионального центра космических улю, обеспечивая информационное взаимодействие региональных и местных органов государственной власти.

Таким обраљ, центры космических услуг должны в территориальном разрезе стать с позиции дистрио. отора потребителем космоснимков с функциями дешифрирования космоснимков -матической обработки, наполнения слоёв атрибутивной информацией, создания pe янального (муниципального) архива и предоставления многоаспектной пространств ной информации ОГУ или ОМСУ.

В ер рение РКД-Т связано с непрерывной работой с космоснимками, которые, в идеале, должн ұокрывать всю территорию региона. Такое покрытие можно ожидать через 2-3 года пос оя ного применения РКД-Т, особенно в случае, если одним из нормативных факторов оценки уровня управления территориями станет показатель применимости результатов космической деятельности при принятии решений ОГУ (ОМСУ). 
В любом случае, чем выше (в \%) и разнообразней с позиции масштаба (разрешения снимков) покрытие территории, тем проще для используемых РКД-Т подготовить топооснову (это может быть оцифрованная карта или ранее использованный, а значит, и привязанный к местности космоснимок или их композиция), позиционировать событие, вызвавшее проблему, подготовить пространственную информацию для ЛПР, задача которого - ликвидация той проблемы.

Итак, необходимо последовательное наращивание покрытия перритории космоснимками со спутников самого различного разрешения по мере применени. РКД-Т, а там, где это позволяет обстановка (в первую очередь - финансовая, во вторуґ кадровая), приобретать снимки, которые, с высокой вероятностью, понадобятся я я выполнения государственных функций ЛПР, то есть при выполнении внутренних регламентов функционирования ОГУ и ОМСУ.

Наличие хорошо организованного покрытия территории кос оснимками должно обеспечить специалистам, готовящим пространственную информа и д для ЛПР, оперативно получать сведения о наличии снимков в хранилище данных (X 1 , с указанием масштаба и времени съёмки, покрытии необходимых частей территории конечно, «белых пятен» в покрытии. Предполагается, что размещённые в ХД снц мки прошли предварительную обработку.

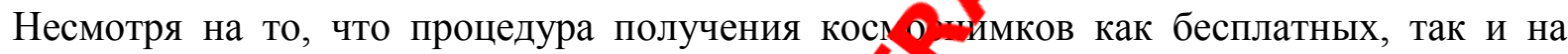
коммерческой основе достаточно проста, заказ сним требует конкретизации параметров, отвечающих требованиям сложившейся на терриг руи ситуации и применяемым РКД-Т (время и период съёмки, разрешение и др.), для че чужна специализированная подготовка.

Привлечение ЦКУ позволит упорядочить работу с пространственной информацией в регионах, обеспечит быстрый доступ потребителя к ДДЗЗ и, что самое главное, - к технологии получения результатов от применения РКД-Т.

Фактически РЦКУ - небольци коллектив профессионально подготовленных специалистов по работе с пространст нной информацией. Как правило, задачи МЦКУ во многом пересекаются с задачами р гионального уровня, дело только в масштабности решаемых задач. Более того, с т Кк зрения РКД-Т, задачи по тематике лесопользования, сельского хозяйства, дорожного хозяйства и ряда других, решение которых регламентировано для ОМСУ, являются пбздачами, определёнными регламентами ОГУ, хотя соответствующие государств मे ые функции у них несколько разнятся.

Ясно, что при нали РЦКУ существование отдельных МЦКУ затратно, а значит, и неэффективно. Целесољразно иметь отдельные ГИС-порталы для каждого (или группы) муниципального образова̊ния, а вся работа по подготовке пространственной информации для принятия решений ॠ ММСУ должна осуществляться РЦКУ, а затем, через виртуальные МЦКУ передават яна ГИС-порталы МО. Таким образом, ГИС-порталы МО будут играть роль классифик

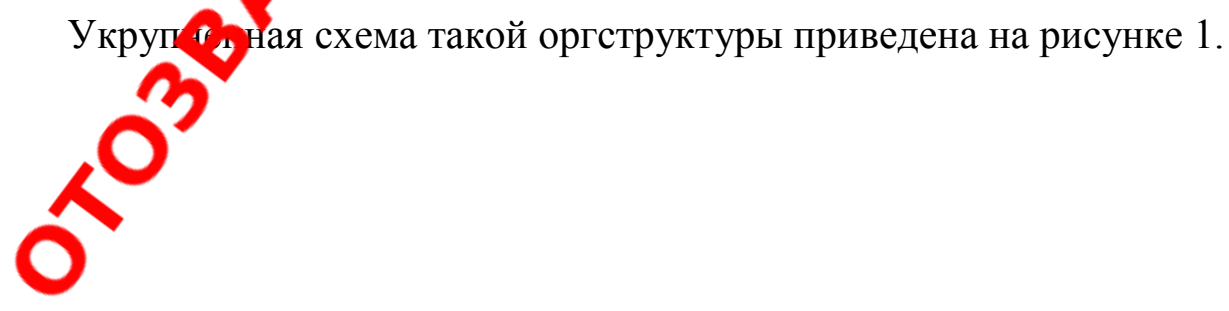




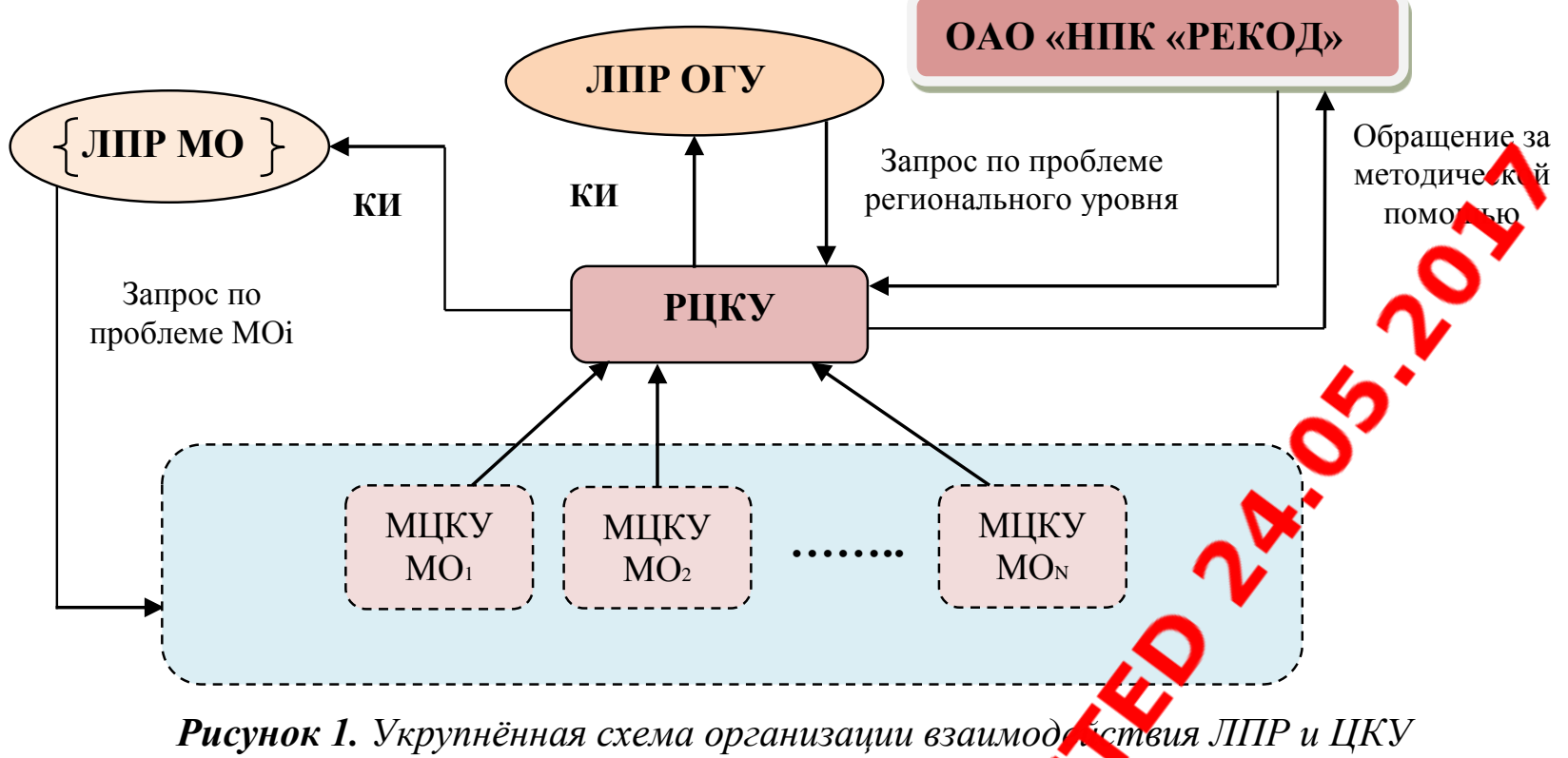

Как показано на рисунке 1 , ОАО «НПК «РЕКОД», яв єсь разработчиком технологий применения РКД в управлении территориями, должно вза тодействовать с региональными центрами космических услуг, в первую очередь это ока ае методической помощи, а также возможная технологическая помощь для решения сложых задач.

Конечно, могут существовать МO, им жщие большой промышленный и образовательный потенциал, большое население и срьёзные амбиции по поводу применения РКД-Т. Возможно, такие МО могут содержать МЦКУ, но, видимо, это скорее исключение из реальных возможностей регионов.

В заключение отметим, что на сегодняшний момент созданы и функционируют ЦКУ в ряде регионов, частично реализующие фоеописанные функции. Дальнейшее развитие сети региональных ЦКУ во многом зависитт,доступности космоснимков высокого разрешения с отечественных космических аппарат в

\section{८ ЛИТЕРАТУРА}

1. Постановление Џравительства Российской Федерации от 28 февраля 2015 г. N 182 о внесұии изменений в постановление Правительства Российской Федерации бт 10 июня 2005 г. N 370 «Об утверждении Положения о планир вании космических съемок, приеме, обработке и распространении даннь хистанционного зондирования Земли высокого линейного разрешения на м жности с космических аппаратов типа «Ресурс-ДК». 
Bezborodov Vyacheslav Georgievich

Russian state university of tourism and service, Russia, Moscow Scientific and production corporation «REKOD», Russia, Moscow E-mail: bezborodov@recod.ru

Dukarsky Oleg Meerovitch Scientific and production corporation «REKOD», Ru Sh Moscow E-mail: duknky@ rekod.ru

Tryapkin Dmit Sergeevich Scientific and production corporation «REK D 》, Russia, Moscow E-man.-dtryapkin@rekod.ru Ushakov Pos an Gennad'evich Scientific and production corporation «KEKOD», Russia, Moscow

\title{
Organization of mass access to spatial ir formation and its analysis for territorial deve opment
}

\begin{abstract}
The issues of access to space informaton of government regions and local authorities, enhance the quality of management decisions.

The detailed review of issues covering the are of the region satellite images of varying resolution and the estimated cost of such work.

Describes the function of leading space-based information to the form, intensifying the activity of decision-makers (additional alternatives), and the visibility of decisions.
\end{abstract}

Based on the above analysis functions concludes that access to space-based information available in the organization of special units that implement these functions in the regions, which are called "center space services".

The general requirements to the $\mathrm{c}$ ter of the space services mentioned: implementation of a simple, direct and quick access decisi -makers, to the spatial data to ensure maximum achievable its relevance, thematic analysis of $\$$ natial information and to ensure the diversity of its representation, participation in navigation task

Discusses regional and municipal centers for space services.

Regional centers a defined as the operator, providing within the region to rapid all interested users in his area of responsibility precision and reliable information in a single coordinate system and real-time. The main consumers of information are the structural units of the Russian Federation oull as local government municipalities.

Civic Cen $⿴$ - is defined as a means of information support of the municipal government and is designed to $\mathrm{re}$ and comprehensive utilization of local authorities based information to support managemen 2 isisions.

It S s nown that in the presence of regional centers for space services the existence of separate municip centers for space services is costly and inefficient, so training is offered for spatial infor mo the in the interests of the region and in the interests of municipalities to implement the regional centers for space services and then send it to the portals of municipalities. 
Noting the positive contact of the regional centers for space services with JSC "SPC" REKOD "in the first place is methodical assistance, as well as the possibility of technological assistance for solving complex problems.

It is predicted that the further development of a network of regional centers for space $A$ ices largely depends on the availability of remote sensing data on the basis of high-resolution satellite imagery from domestic spacecraft.

Keywords: remote sensing; access to space-based information; spatial informatio covering territory with space images; territory management; the center of the space services

\section{REFERENCES}

1. Resolution of the Government of the Russian Federation on Fe ruary 28, 2015 N 182 to amend the Decree of the Government of the Russia 1 ederation dated June 10, 2005 N 370 "On approval of the planning of space shor no, receiving, processing and dissemination of remote sensing data of high linear armits for areas with spacecraft such as "Resource-DK".
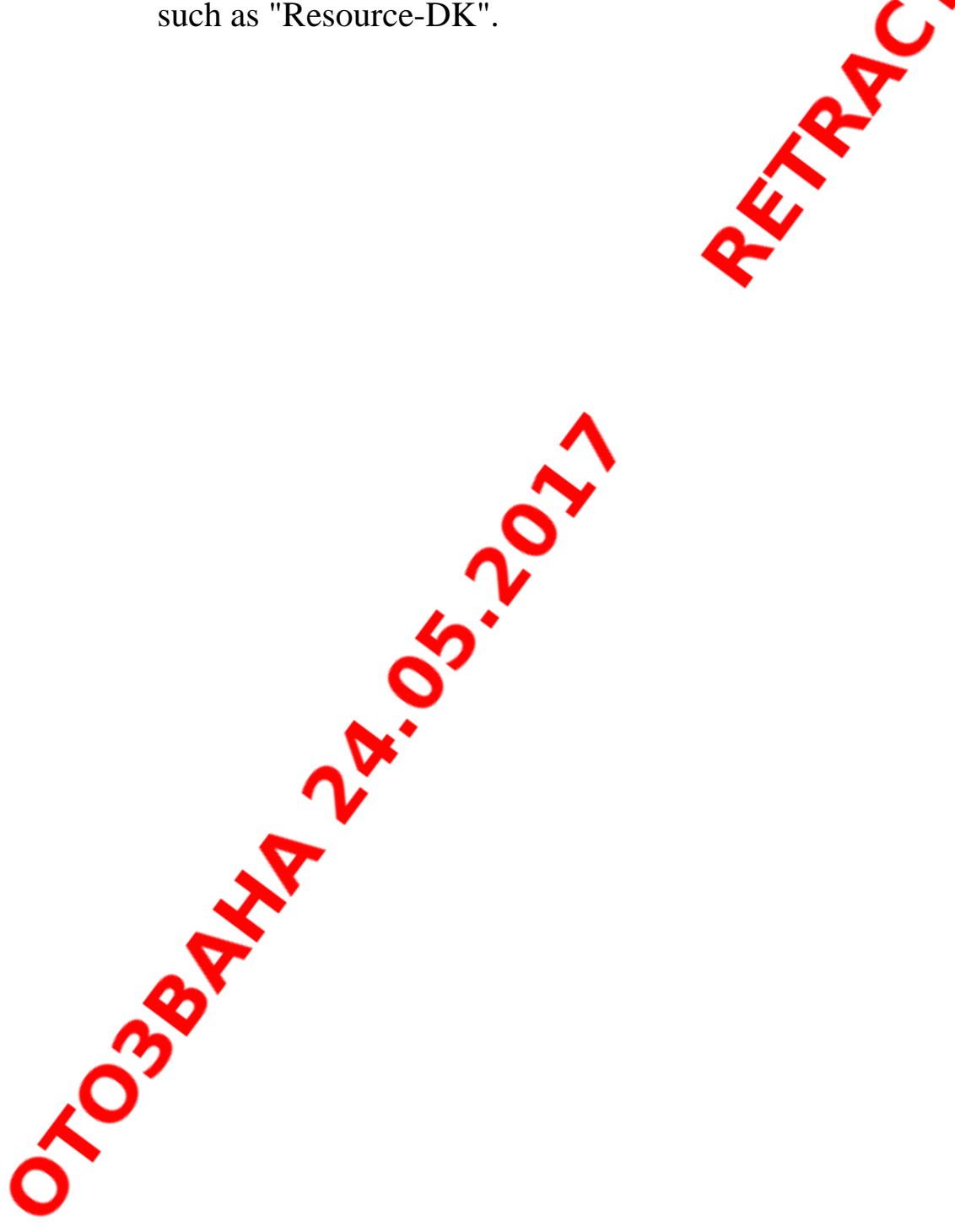